\title{
Application of Learning Community in Paper Teaching
}

\author{
Lin $\operatorname{Lin}^{1, a}$, Yuzhu Han ${ }^{2, b}$ \\ ${ }^{1}$ Institute for Higher Education, Jilin Agricultural University, Changchun,130118, China, \\ 2 Jilin Agricultural University, Changchun, 130118, China \\ aemail: linlinjlau@126.com, bemail:linlinjlau@126.com
}

Keywords: learning community; paper teaching; education feature

\begin{abstract}
Learning community was made a tentative application in 《Breeding Science of Horticultural Plant》 paper teaching. And teaching reflection was summarized including concept of learning community, education feature, practice effects and teaching experience.
\end{abstract}

\section{Application of Learning Communities in Classroom Teaching}

Horticultural Plant Breeding is the excellent course of Jilin Province, and since 2007, the teaching group has made great endeavors in innovation of teaching methods and is now deeply aware that advanced teaching methods are the essence for improving teaching quality. In 2015, the teaching group leader participated in the study program on teaching methods for higher education in New Zealand lasting over three months, from which, the group leader gained a complete understanding and mastery of the teaching method and principle concerning learning communities with the focus of students. After coming back, the group leader applied the method into the course of Horticultural Plant Breeding and found in the teaching process that students' learning interest, degree of involvement, and active learning increased dramatically. After the class, an investigation on some of the students showed that most of the students accepted with pleasure and liked the method because they found it quite novel and through the method, they could enjoy the pleasure of teamwork, open-mindedness and enhance their initiative in listening to the class, and even some students disliking studying were attracted to the class. In addition, for other students, by this teaching method, they felt the sense of presence and made a self-breakthrough to some extent. The teaching method and process of the application of learning communities in course teaching are as shown in the following:

\subsection{Ice-breaking grouping}

Construction of efficient learning communities is directly related to scientific and reasonable grouping. Obvious differences would show in the students during learning process, including learning initiative, exploration capability, divergent thinking, problem solving ability etc. Students with slight differences are grouped together, which are good for cultivation of the divergent thinking and problem solving ability of students. For this reason, heterogeneous grouping is more conducive to simulating learning interest and effective cooperation of students ${ }^{[1]}$. For instance, heterogeneous grouping can be carried out in accordance with learning type and gender of the students. Each group consists of 3 - 5 students with one student as the group leader, who guides group members to complete the tasks assigned by teachers as required.

\subsection{Interactive communication}

During the class, teaching, self-study and discussion is interwoven with each other, that is to say, questions that can be understood or overcame by students themselves through attempts shall be left to students; the questions that cannot be understood or overcame by students themselves shall be solved by combination of teaching and self-study, and progressive, open-ended and thought-provoking questions shall be put forward. Besides, in the class, group discussion shall be used to provide students with the platform and opportunity to learn from and communicate with 
each other so as to promote active learning and exploration of students independently. It shall be noted that the questions or tasks set up by teachers shall be open, practical, appropriate and challenging to some extent with due consideration given to features of students and stimulation of students' interest. Teachers shall offer necessary guidance on cooperative learning for the communities, and listen to, participate in, encourage and inspire students' communication, so that students can fully express their ideas and thoughts. Meanwhile, the discussion is centered on the same topic from the beginning to the end of the discussion, thus the class can be both active and academically serious $^{[1]}$.

\subsection{Multiple evaluation}

Teachers shall adopt combination of formative and summative evaluation of group learning. To be specific, the formative assessment is the open evaluation, in which, teachers and students participate jointly, students' performance in communication of the communities are emphasized, relative evaluation and moderate competition are carried out among students and groups. That is to say, the formative assessment is both aimed at evaluation of the whole group but also the role in the program and degree of progress of each student. While, the summative evaluation mainly focuses on students' mastery of professional knowledge and comprehensive skill proficiency.

\section{Definition of Learning Communities}

Learning communities was formally put forward as a definition in 1990 by an American educationalist who wrote in an article titled Why Should Schools Be Learning Communities: "a learning community refers to an organization consisting of learners and their facilitators, they communicate with each other in the process of learning, share various learning resources and accomplish learning tasks jointly, thus, interactional and mutual promoting interpersonal relationships are established among the members" ${ }^{[2]}$. It requires the learners to pay close attention to interpersonal communication in learning practices, and to rebuild their identities by imitation and consultation by means of mutual cooperation so as to help the learners using different learning methods complement each other and accomplish various learning tasks ${ }^{[1]}$. It fosters a communication-oriented class by eradicating the traditional classroom teaching model and has profound significance for promoting mutual development of teachers and students.

\section{Educational Characteristics of Learning Communities}

\subsection{Sharing and interaction during learning process that provides a good communication environment which is good for stimulating classroom dynamics and realizing teaching targets.}

The traditional classroom teaching represented by Herbart is mainly the imparting teaching, under which, interaction and communication between teachers and students are in lack, and students are only expected to cram for textbook knowledge in the class. In that case, the knowledge acquired by students is inert and can hardly be applied into situations in real life. However, in the learning communities, the members share learning resources and communicate with each their learning experience and feelings, and make it a cultural atmosphere. In addition, learning communities promote information exchange among members, encourage them to share the wisdom and experience of the group, let them rethink and then reach census on some questions, and promote cognitive competence of the individual learner as well.

\subsection{Giving full play to students' dissimilarity and centering on students}

Due to influence of heredity, learning and living environment, all the student have their unique personality traits and are different from each other, thus, uniform teaching method would certainly 
stunt students' individuality, but learning communities are students-oriented and can give full play to students' potential and dissimilarity, by which, interaction and communication among the members are increased, personal traits of students are fully exhibited and innovation ability is gradually fostered ${ }^{[3]}$.

\subsection{Learning communities are conducive to innovation}

Members in the learning communities share knowledge by barrier-free communication, cooperate with each other and exchange their views, and constantly "rebuild" their knowledge system under inspiration and stimulation from others to stimulate their hidden innovative thinking, and seek common ground while reserving differences. In this way, students' initiative, consciousness and creativity are brought into full play and through different forms of internalization and externalization, the students’ knowledge, abilities and qualities are fully developed.

\subsection{Shifting the role of teachers and students and establishing a solid teacher-student relationship}

Teachers are no longer the leading characters in classroom, they more often play a role of director in working out content of courses, links and questions, analyzing the knowledge points to be learned by students, designing progressive, open-ended and thought-provoking questions, and preparing documents for class discussion of students before class; and in class, teachers shall combine teaching, asking and guiding together, give directions to students in key points of what is hard to understood or mastered by students themselves, and raise open-ended questions for group discussion of students so as to mobilize students' thinking and encourage them to think. Most importantly, teachers can write students' different viewpoints on the blackboard and give a summary after students returning the discussion results; after class, teachers shall assign students the tasks to look up documents by themselves and the tasks needing cooperation ${ }^{[4]}$.

Correspondingly, students shifted from supporting characteristics into the leading characters, and at the same time, their active exploration, discovering and building of the system of the knowledge they have learned are attached to high importance. Classroom including its relevant extra-curricular activities become the stage for students to perform after individual training and group training. The learning contents of students expand from textbooks to the entire knowledge system and all the practice fields related to the course.

In learning communities, teachers and learners share all sorts of learning resources instead of teachers exclusively enjoying teaching resources. Thus, teachers shall acquire a wider range of subject knowledge, more profound culture deposits and be proficient in pedagogy and psychology. That is to say, teachers shall make efforts to create a classroom atmosphere under psychological safety to enable learners to have the courage to express and ask questions, and encourage them to communicate on the content they are exploring so as to enhance knowledge of the learners in interactive communication and promote their learning in a real sense under such a relaxed atmosphere.

\section{Practical Results and Reflections on Teaching}

\subsection{Practical results}

After the class, an investigation on some of the students showed that most of the students accepted with pleasure and liked the method because they found it quite novel and they could enjoy the pleasure of teamwork, open-mindedness and enhance their initiative in listening to the class, and even some students disliking studying were attracted to the class. In addition, for other students, by this teaching method, they felt the sense of presence and made a self-breakthrough to some extent. Besides, this teaching method can deepen the cognition degree of classroom knowledge and is characterized with complementary of advantages, active communication, collective participation for 
it not only allow group members to expect others to work hard but also amplify their own efforts ${ }^{[5]}$.

\subsection{Reflections on teaching}

Teaching through learning communities manifest students’ imitative, teaching interactivity, buildability of knowledge and gives full expression to modern educational concepts, thus, it meet the requirement of contemporary higher education. However, such teaching method requires the teachers to possess certain teaching experience, strong ability in classroom control and good command of knowledge. It is a key point in implementation of this teaching method to scientifically design some smart, novel and thought-provoking questions for students by teachers. Therefore, in lesson preparation, teachers shall analyze the knowledge points to be learned by students, design the progressive, open-ended and thought-provoking questions, with which, students need to look up documents, communicate with each other and discuss in groups to handle. It shall be noted that degree of involvement of different students and listening to and learning from others during returning of the discussion results shall be strengthened.

\section{References}

[1] Gao Fang, Art of Group Communication in Construction of Learning Communities for Higher Vocational College Classroom Learning [J], Vocational \& Technical Education Forum, 2012 (17);

[2] Liu Xiaolong, Feng Xuejuan Origin and Education Features of “Learning Communities” [J], Jiangsu Education Research, 2011 (7);

[3] Peng Xinhua, Effectiveness of Constructing Learning Communities in Enhancing Teacher-Student Communication in Class [J], Inheritance Innovation, 2009 (9);

[4] Zhang Wei, Guo Yongzhi, An Empirical Study on Learning Pattern of Learning Communities [J], Science of Education, 2012 (5);

[5] Chanyao. The Classroom: A Limited Learning Community [J], Education Exploration, 2010 (02). 